\title{
Deceit, principles and philosophical medical ethics
}

\author{
Raanan Gillon Imperial College, St Mary's Hospital Medical School and King's College, London University
}

'Surely we can all imagine circumstances in which the possibility of reposeful death was positively destroyed by a doctor bearing down (with the latest textbook on "philosophical medical ethics" in his hand) upon a vulnerable dependent patient, demanding that he react to his predicament as an autonomous moral individual who must be ready to face all the awful facts about his illness' warns Mr Byrne in his commentary (1) on Dr Dunbar's paper (2) on deceiving the dying, in this issue of the journal. And he asks: 'What happens, as Dunbar himself notes, if someone does not want to be autonomous and does not want all the medical truth?'

Before addressing the substantive issue it is worth questioning $\mathrm{Mr}$ Byrne's implicit attack on the developing discipline of philosophical medical ethics. In particular, where are the books on the subject that require or even encourage the crass behaviour he properly castigates from a doctor to his or her patient? According to one book on philosophical medical ethics (it lies conveniently to hand! the point could be made from many other examples in the genre): 'The doctor who really respected his patient's autonomy would discover in a sensitive way, which did not demand a particular answer, what and how much each patient really wanted to know and how much he wished to participate in the decision-making.' - and he would act accordingly (3).

As Dr Higgs states in his commentary on $\mathrm{Dr}$ Dunbar's paper: 'Nothing in any modern textbooks of philosophical medical ethics that I know or respect would advise the doctor, 'bearing down on the vulnerable patient', to see respect for autonomy in terms of unwarranted disclosure to an unwilling patient. The important question is what or how much does this patient want to know. This is defined by the patient...' (4). Even Dr Veatch, one of the most redoubtable philosophical defenders of the relevance of respect for autonomy to medical ethics states: 'Imposing information on a person would violate the individual's autonomy just as withholding information would' (5). And Dr Dunbar in the paper criticised by Mr Byrne emphasises the nuances of clinical ethics, 'the distance between theory and practice', and his belief that while 'the principle of veracity provides a sense of direction', it is not absolute. 'Ethical principles resemble guidelines on a map in an unknown landscape rather than reflecting immutable laws of the universe. They are not absolutes' (2).

There may be misguided philosophers writing books about philosophical medical ethics that recommend the behaviour imagined by $\mathrm{Mr}$ Byrne, but on the whole the addition of philosophical skills, including those of $\mathrm{Mr}$ Byrne, has surely been a welcome development in the contemporary concern of doctors and other health care workers to reflect critically about the ethical aspects of their work, and it seems a pity to disparage them.

The brief answer - from a wide variety of contemporary perspectives in philosophical medical ethics - to Mr Byrne's first and last question - what happens if someone does not want to be autonomous and does not want all the medical truth - is similar to Mr Byrne's own answer: presumptively he should not have it imposed on him. Imposing such information against a patient's wishes is not, in the normal case, beneficial, may well be harmful, and far from being required by the principle of respect for autonomy, is precisely a failure to respect that patient's autonomy. Any clinician will know of patients who clearly do not want to be given bad news - they simply want their doctor to get on with doing the best possible to help them, and firmly reject offers to discuss the medical findings further. But clinicians will also know that many patients, if given such opportunities for discussion, not just once but intermittently, and if given them in a way that makes it clear that time and empathy are available, will wish to be told about their medical situation and the anticipated outcome, even when both parties know that such discussions are likely to produce intense grief.

There are well known standard arguments for concluding that deceit in medical practice, even in terminal care, is prima facie wrong (even if sometimes it may be justified) $(6,7,8)$ and they are deployed in $\mathrm{Dr}$ Dunbar's consideration of a specific case (2). Agreeing with Dr Dunbar that violation of trust is one of the moral problems of deceit Mr Byrne states: "What makes deceit wrong is that it is a violation of trust and thus of the moral relationship which ought to be established between doctor and patient' - and he goes on to add: 'I do not deceive my eight-year-old if I respond to his desperate requests to know if Father Christmas is real, by giving him the reassurance on this 
score he so obviously wants and needs at this point in his childhood. I give him such of the truth as he is ready and capable of accepting but this may be very little'. Now we aren't told precisely what Mr Byrne told his son, but suppose, in a similar hypothetical case one replied to one's son: 'Yes, Father Christmas does exist' then one would surely simply be mistaken if one thought 'I do not deceive my eight-year-old'. That is not to say that one would necessarily have done wrong to deceive one's child, simply to say that one necessarily has deceived him - necessarily by virtue of the meaning of the word 'deceive'. It is a further issue whether one might justify one's deceit in such cases and in a journal of educational psychology or parenthood the issue might be worth pursuing. In this context the importance of the example lies in the two quite distinct points that arise from Mr Byrne's analysis: first the question of what constitutes deceit and second the question of what makes deceit wrong.

In the ordinary language use of 'deceit' (not to mention the dictionary definitions), if one leads someone else to believe what is false one deceives that person. In clinical practice if one leads a person to believe that all is medically well when one knows that it isn't then one deceives that person. If one leads a person to believe that he or she does not have cancer when one knows that he or she does have cancer then one deceives that person. If one believes otherwise then one deceives oneself, by leading oneself to believe what is false! What about Mr Byrne's interesting claim that what makes deceit wrong is the violation of trust and thus of the moral relationship which ought to be established between doctor and patient? There seems little doubt that such a violation of a special trust is sufficient to make deceit wrong. Is it also necessary? Suppose one has no particular moral relationship with another person and one deceives him, is that not prima facie wrong? Indeed is it not prima facie more likely to be wrong than in a special relationship simply because of the unlikelihood of a prior agreement that deceit would be mutually acceptable? One reasonable response might be to suggest that all our relationships with other people - even such minimal relationships as when one stranger tells another the time on request are moral relationships and thus involve some degree of trust. But that response would simply confirm that the normal moral relationship between people, even between total strangers, prima facie requires us to avoid deceiving each other. Thus by such an analysis too, deceit is prima facie wrong.

Such a conclusion accords with very widespread social norms - deceit must be one of the most vigorously punished moral transgressions in childhood. Here is not the place to try to elucidate why deceit is so widely and intensively regarded as wrong, but among the reasons may be that the very possibility of language is predicated on a norm of truthfulness: (imagine trying to teach or learn to use language without such a norm). For whatever reason, truthfulness and non-deceit are widely accepted as basic moral norms in all our interpersonal interactions and while as $\mathrm{Mr}$ Byrne points out they may sometimes be properly overridden, good moral reasons are required for doing so.

Mr Byrne, in his stimulating brief response to Dunbar, and in a more extensive discussion elsewhere (9), also suggests that an ethics of friendship, of relationships and of virtues would be more useful to medical ethics than concern with rules or principles. There are of course a variety of types of moral theory competing for the attention of medical and other health care practitioners, their advocates all claiming to be better, more appropriate, more helpful for medical ethics. Virtue theorists, friendship theorists, casuistry theorists, life story or narrative theorists, religious theorists, political theorists, all may believe themselves to have the best type of theory for medical ethics. Pending agreement - not immediately in sight - about which of them is right, an intermediate set of prima facie moral principles, not themselves comprising a moral theory yet compatible with all the competing moral theories, is available for practical application. These are the widely accepted prima facie principles alluded to by Dr Dunbar and originally propounded by Beauchamp and Childress in their textbook (10) respect for people's autonomy, beneficence, nonmaleficence and justice. Of course when they conflict we are left, as Mr Byrne says, with all the work to do. So are we by any other plausible moral theory when moral concerns come into conflict. The enormous advantage of an approach based on agreed prima facie moral principles is that the work concerned can be done in mutual comprehension within a common framework compatible with a huge variety of underlying (overlying?) moral, political and religious theories. We disparage the use of these principles at the risk of losing a very important basis for moral agreement in a world that has too few such bases.

\section{References}

(1) Byrne P. Commentary 1. Comments on an obstructed death. Fournal of medical ethics 1990; 16: 88-89.

(2) Dunbar S. An obstructed death and medical ethics. Fournal of medical ethics 1990; 16: 83-87.

(3) Gillon R. Philosophical medical ethics. Chichester: Wiley, 1986: 115.

(4) Higgs R. Commentary 2. An obstructed death and medical ethics. Fournal of medical ethics 1990; 16: 90-92.

(5) Veatch R. A theory of medical ethics. New York: Basic Books, 1981: 206.

(6) Bok S. Lying - moral choice in public and private life. Hassocks, Sussex: Harvester Press, 1978.

(7) Higgs R. On telling patients the truth. In: Lockwood M, ed. Moral dilemmas in modern medicine. Oxford: Oxford University Press, 1985: 187-202.

(8) See reference (3): 100-105.

(9) Byrne P. Authority, social policy, and the doctor-patient relationship. In: Dunstan G R, Shinebourne E A, eds. Doctors' decisions - ethical conflicts in medical practice. Oxford: Oxford University Press, 1989: 228-243.

(10) Beauchamp R, Childress J. Principles of biomedical ethics (3rd ed). Oxford: Oxford University Press, 1990. 